\title{
ON EPISTEMOLOGY OF CONSTRUCTION ENGINEERING AND MANAGEMENT
}

\author{
Lauri Koskela $^{1}$, Ergo Pikas ${ }^{2}$, Jarkko Niiranen $^{3}$, Andrea Ferrantelli ${ }^{4}$ and Bhargav Dave ${ }^{5}$
}

\begin{abstract}
In philosophy of science, there have been two different starting points for epistemology: Platonism and Aristotelianism. These two alternative starting points have played a major role also in the formation of fundamental ideas of engineering and management generally as well as in relation to construction. It is contended that an overly Platonic influence on engineering and management has created a number of problems. For solving these problems, beyond mere patching, a more balanced take on Platonism and Aristotelianism is needed.
\end{abstract}

Keywords: Epistemology, Construction Engineering, Construction Management.

\section{INTRODUCTION}

The ubiquity of the problems in construction - both managerial and technical - is well known. For tackling these problems, it is necessary to know whether the root causes for them are abundant and scattered over many domains or whether there are some major root causes that could be remedied through a few concentrated efforts. In this presentation, we contend that there indeed exists one major root cause that has hardly attracted attention, namely unhelpful epistemological (i.e., how we acquire knowledge) choices in engineering and management.

The paper is structured as follows. First, the intellectual origins of engineering and management are examined. The findings made allude to the influence of the timehonoured epistemological contradiction between Plato and Aristotle; this is discussed next, along with the historical diffusion of their views into engineering and management. An analysis of the problems caused by inappropriate epistemological views follows. A brief discussion on conclusions completes the paper.

\section{EPISTEMOLOGICAL ORIGINS OF ENGINEERING AND MANAGEMENT}

\subsection{Rankine - the father of scientific engineering}

The Scot William Rankine consolidated the engineering field of structural mechanics in his books published in the 1850s and 1860s. The book "A manual of applied mechanics" (Rankine 1872) contains his inaugural lecture to the class of civil engineering and mechanics at the University of Glasgow in 1858, titled "Preliminary dissertation on the harmony of theory and practice in mechanics". In many ways, this lecture is his programmatic declaration for a science of engineering.

University of Huddersfield, School of Art, Design and Architecture, 1.koskela@hud.ac.uk

Aalto University, Department of Civil Engineering and Tallinn University of Technology, Faculty of

Engineering

Aalto University, Department of Civil Engineering

Tallinn University of Technology, Faculty of Engineering

Aalto University, Department of Computing 
The novelty he propagated was to utilize natural science, especially physics, for practical purposes in engineering - earlier these two fields had been considered separate. Essentially the question was about engineering design: "to plan a structure or a machine for a given purpose". The use of physical laws made it possible to accurately predict, through deduction, the behaviour of a structure or machine, and this in turn made it possible to pinpoint the best possible, optimal, solution. Thus, he defined the new style of engineering as a "scientifically practical skill which produces the greatest effect with the least possible expenditure of material and work".

According to Rankine, this new engineering contrasts with purely practical knowledge, providing only approximate solutions, based on prompt and sound judgment or an established practical rule. This practical knowledge dominated especially in the realm of making and constructing: "to judge the quality of materials and workmanship, to direct the operations of workmen." Rankine did not hide his value judgment regarding the relative worth of scientific engineering and practical knowledge: "...the engineer or mechanic, who plans and works with understanding of the natural laws that regulate the results of the operations, rises to the dignity of a Sage."

Interestingly, all these hallmarks of scientific engineering exist still today in teaching and research of engineering: basing engineering on physical laws, definition of engineering predominantly as design, emphasis on optimal solutions, and use of deduction as the primary form of reasoning.

\subsection{Shewhart - the father of quality}

The American Walter Shewhart is considered as the seminal contributor to statistical quality control, which later evolved into total quality control. His work was stimulated in the 1920 s by the rapidly evolving mass production, which needed methods for ensuring consistent quality of products.

Shewhart (1931) was not much interested in engineering design but he needed it as his starting point (he discusses human wants as the starting point of mass production):

The first step of the engineer in trying to satisfy these wants is therefore that of translating as nearly as possible these wants into the physical characteristics of the thing manufactured to satisfy these wants. In taking this step intuition and judgment play an important role as well as the broad knowledge of the human element involved in the wants of individuals.

Here, Shewhart fails to mention the use of physical laws in engineering. Indeed, he is more interested in production:

The second step of the engineer is to set up ways and means of obtaining a product which will differ from the arbitrarily set standards for these quality characteristics by no more than may be left to chance.

Shewhart's concern was to reduce the gap between the intended and the achieved. How is this gap reduced? Through the method of science (Shewhart 1939):

Let us recall the three steps of control: specification, production, and judgement of quality. [...] In fact these three steps must go in a circle instead of in a straight line [...]. It may be helpful to think of the three steps in the mass production process as steps in the scientific method. In this sense, specification, production, and inspection correspond respectively to making a hypothesis, carrying out an experiment, and testing the hypothesis. These three steps constitute a dynamic scientific process of acquiring knowledge.

These ideas were later transformed into the PDCA cycle (Plan-Do-Check-Act), now widely known and applied in quality work and lean production.

Again, the basic ideas of Shewhart are today widely used in industrial engineering, especially in practices of quality and lean production: basing industrial engineering on the scientific method, focusing industrial engineering on production, emphasis on 
improvement and use of induction (from empirical experimentation) as the primary form of reasoning.

\subsection{Comparison between Rankine and Shewhart}

There are definite differences between Rankine's and Shewhart's ideas. Rankine's main interest is in design in contrast to Shewhart's focus on production. In engineering, Rankine wants to use the results of scientific research. In turn, Shewhart suggests the use of the scientific method - however, the hypothesis to be tested is not flowing from science but from the practical production context. In so doing, Shewhart (and his followers) popularizes the scientific method, it should be used in practical affairs, outside science. Rankine focuses on what is intended, the ideal or optimal solution. Shewhart's interest is more in reducing the gap between intended and achieved. In Rankine's scheme, reasoning proceeds forward, from ideas to the material world through deduction. Although Shewhart hardly treats matters related to reasoning, it is fair to conclude that reasoning backwards is also needed.

Now, the difference between Rankine and Shewhart has interesting initial similarities to a much older opposition, namely views on science by Plato and Aristotle.

\subsection{Epistemologies of Plato and Aristotle}

Plato believed that full understanding of the world cannot rely only on perception which provides only a limited and naive view of Nature. Fundamentally, perception is based on constant change. Plato therefore discerns between perceptible things (which are unstable and thus unreliable) on one side, and the so-called "Forms" on the other. The latter are the only reliable sources of knowledge. Proper scientific reasoning thus occurs only via deduction from Forms (or specifically, axioms) to something that can be compared to observations (Ross 1951). Thus, according to Plato, the most fundamental essence of reality does not belong to the material world, but to the realm of abstract concepts, the world of ideas.

In contrast, Plato's pupil Aristotle is convinced that proper scientific knowledge is grounded on perception. Aristotelian science is about explanation, namely, discovering causes behind observed phenomena. His scientific method always begins with specific cases, via observations, and seeks for explanation through induction. This is then applied to other particular cases by deduction.

Platonism, also called rationalism, and Aristotelianism, also called empiricism, have then survived to the present time as two competing epistemological alternatives in science (Fig. 1). At the moment, certain parts of physics, especially string theory, strongly subscribe to Platonism, whilst data science, for example, is Aristotelian in its extreme empiricism.

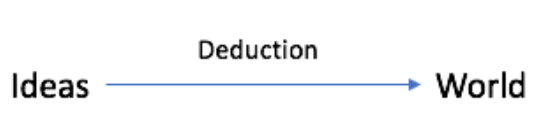

a

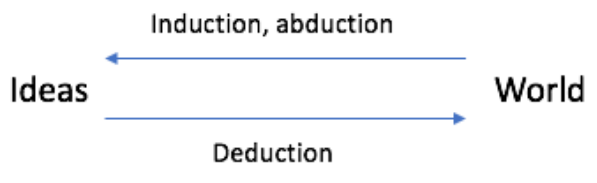

b

Figure 1. a) Platonic and b) Aristotelian epistemology 


\section{DIFFUSION OF EPISTEMOLOGICAL COMMITMENTS INTO ENGINEERING AND MANAGEMENT}

The context considered here, namely engineering and management, is of course different to science. Nevertheless, the epistemological questions require to be responded if progress is to be made: from where can we have knowledge to base our design and planning activities, or any productive action? Those leaning to Platonism argue that reason or theoretical knowledge - broadly, the world of ideas - should provide the basis. In turn, those subscribing to Aristotle contend that it is the empirical observation that should be taken as a starting point.

As exemplified through Rankine, the very idea of engineering is to start from theoretical knowledge; also other hallmarks of Platonism are plain. Although more Aristotelian views have also existed, especially in the US the Platonic view of engineering gained a dominating position after the Second World War (Seely 1999).

The emergence of managerial disciplines is connected to the famous reports on the future management education in the US published in 1959 (Koskela 2017). They proposed three root stems for business research and education: behavioural science, economics and quantitative methods. Out of these, economics and quantitative methods were Platonic, whereas behavioural science was promoted as an empirical science. Out of these, especially economics, with strong Platonic undercurrents, has been influential. In economics, the current neoclassical paradigm gained foothold after 1870, with a tipping point in the 1930s. It adopted contemporaneous physics as its methodological model, and thus its axiomatic method. Optimal decision on allocation of scarce resources came to be the leading economic concept.

Certainly, there have been counter-currents. The quality movement that emerged from Shewhart's seminal efforts can be seen as the flag-bearer of the Aristotelian approach. The related lean movement, foreshadowed by scientific management and essentially brought into completion as the Toyota Production System, is similarly Aristotelian. Especially, the concept of waste implies that one starts from the material world.

All in all, it can be said that in the realm of productive activities, engineering, production and management, Platonic approaches have provided the dominant worldview in the latter half of the $20^{\text {th }}$ century, and still in the beginning of this century.

\section{EPISTEMOLOGICAL PROBLEMS IN CONSTRUCTION ENGINEERING AND MANAGEMENT}

The general intellectual trends described above have trickled down to construction through education (especially at the university level), professional institutions and methods. They have been offered as modern and superior alternatives to craft-based, experiential methods in construction, but of course they have not completely substituted for them. Unfortunately, a number of problems, related especially to the overly Platonic orientation, have also been transmitted.

\subsection{Construction Engineering}

The genesis of scientific engineering, as a Platonic endeavour, has directly contributed to several problems or shortcomings, to be covered next. 


\subsubsection{Preoccupation with design at the cost of other stages}

As defined by Rankine, engineering is involved in design of machines and structures; the realization of these is left to men having practical knowledge (although not explicitly stated, it is obvious that the operation and maintenance is thought of in the same way by Rankine). This preoccupation is visible in the still widely known definition of engineering by the American Engineers' Council for Professional Development ${ }^{6}$ (ECPD):

The creative application of scientific principles to design or develop structures, machines, apparatus, or manufacturing processes, or works utilizing them singly or in combination; or to construct or operate the same with full cognizance of their design; or to forecast their behavior under specific operating conditions; all as respects an intended function, economics of operation or safety to life and property.

Thus, although construction and operation are now recognized as valid areas for engineering, they should be looked through the lens of design. However, construction and operation remain underdeveloped areas of engineering. In addition, the Platonic attitude implies that in design, subsequent stages are hardly taken into account. The following anecdote from an ethnographic study of an engineering office is revealing (Demian and Fruchter 2006):

Bart is very much old school in that a building is just an assembly of details, and that there's nothing wrong with drawing one detail and completely ignoring the fact that there is another detail that must interface with it. He just draws all of these details independently and expects the contractor to figure out how they all fit together.

\subsubsection{Preoccupation with optimality at the cost of gap between optimal solution and what is achieved}

Already for Rankine, the optimality of the solution was one hallmark of scientific engineering. This idea of optimality has been further strengthened by the rise of modern economics from the 1930's onwards as well as the evolution of quantitative methods somewhat later, leading to the approach of "optimal design" from 1960 onwards. However, there are two problems confronting this idea. As already Shewhart identified, the use environment of products wildly varies, making the determination of one single optimum difficult if not impossible. The methods of robust design (Taguchi \& Clausing 1990) have been developed to counter this difficulty.

The other difficulty is that an optimum exists only in the world of ideas; when it is implemented in the material world, the achievement will more or less deviate from the optimum. There is a settled term for this deviation in quality and production engineering: waste. This phenomenon of waste is troublesome for those subscribing to the Platonic view, and it is turned down in different ways. An argument flowing from the Platonic approach itself is that waste belongs to the natural, varying imperfections of the material world and is of low interest in comparison to the pursuit of eternal truths in the ideal world. Another argument is that optimum as such eliminates waste (OECD 1972): "It is also clear that optimum production, which by definition means no wastage and the best use of available resources...”. A third popular argument is that if there is a gap between ideal and material world, it is a fault of your own or of somebody else. Indeed, so incompatible are the concepts of optimum and waste that along with the diffusion of the idea of optimal

\footnotetext{
${ }^{6}$ ECPD changed its name to Accreditation Board for Engineering and Technology (ABET) in 1980. For comparison, the current definition of engineering by ABET is as follows: The profession in which a knowledge of the mathematical and natural sciences gained by study, experience, and practice is applied with judgment to develop ways to utilize economically the materials and forces of nature for the benefit of mankind.
} 
allocation of resources from the (then new) economics after the Second World War, a stark reduction in the use of the term waste occurred (Koskela, Sacks \& Rooke 2012).

\subsubsection{Preoccupation with pre-existing knowledge at the cost of contextually captured knowledge}

For Rankine, engineering was utilization of physical laws for the design of machines and structures. This view of engineering has persisted. Unfortunately, this overshadows the possibility and need for acquiring knowledge related to the task context, or through scientific experimentation. Recently, there have been calls to add problem analysis into the engineering curriculum (Downey 2005). The benefits of acquiring knowledge through experimentation, trials and tests in engineering (and product development) has in the last decades been emphasized by many authors (Thomke 1998) and in approaches such as design thinking (Brown 2008). In construction, these developments have, for their part, been reflected in the shift of focus from physical models to computer models. The advance of Building Information Modelling has been instrumental in this respect.

\subsubsection{Preoccupation with the viewpoint of one discipline}

Clausing (1994) sees that the traditional design process has not moved far enough beyond partial design, i.e., design from the point of view of one engineering discipline. Thus, according to Clausing, the traditional approach suffers from failure of co-operation (missing unity within the team) and failure of process (missing clarity with regard to the activities). This situation has often been called silo mentality; designers prepare designs from the point of view of their own discipline (without much taking needs of other disciplines or stages into account) and just send them to the other designers or next stages. The weakness of this approach is now widely recognized.

\subsubsection{Preoccupation with deduction at the cost of other types of reasoning}

According to Rankine, the type of reasoning associated with engineering is reasoning forward (from ideas to the world), deduction. Deduction is especially evident in the task often called analysis; given a structure, determine its behaviour. In engineering, the creative design activity has been called synthesis but this term hardly carries any widely agreed theoretical understanding.

Reasoning proceeding in the reverse order, backwards, is needed when we start from observation on the material world and want to create knowledge into the world of ideas. Reasoning backwards takes many forms, such as regressive reasoning (reverse of deduction), induction (generalization from a sample) and abduction (creative leap to something new). All these are needed in design and problem-solving, and also when analysing waste for the sake of improvement. The problem has been that systematic teaching and training on these types of backwards reasoning is more or less absent from the curricula of engineering schools. In this way, education reinforces the Platonic tendencies of engineering. Indeed, one of the difficulties related to the concept of waste is that investigation of waste requires less known reasoning approaches, rather than the familiar approach of deduction.

\subsection{Construction Management}

\subsubsection{Production planning and management}

The two well-known approaches to production management, push and pull, have their epistemological interpretation. As it is well-known, push is based on a plan, and pull on the state of the production system. The former is related to the world of ideas, the latter to 
the material world. The wide experience shows that using (Aristotelian) pushing and pulling is widely superior to (Platonic) pushing only.

In construction, push-based production management emerged with the invention of Critical Path Method (CPM) in 1959. CPM was developed in the framework of operations research, under strong Platonic influence (Koskela \& al. 2014). Thus, the question is about an optimal plan that pushes tasks into execution. In case of a deviation from the plan, the primary goal is to do adjustments for reaching back to the original plan. Beyond that, there is no place for learning from observations on execution. Interestingly, verification and validation are not only missing in a CPM plan, but they have been absent also in relation to the CPM as a method. Jaafari (1984), after reviewing six themes of critique against the CPM, states: "...there is nothing inherently wrong in either CPM concept or the subsequent schedules resulted from its analysis, the fault lies in the way it is applied in practice." Of course, this attitude is part and parcel in the Platonic tradition: the starting point in the world of ideas must be correct, it is the execution in the messy material world that is the cause of any problems.

In the beginning of the 1990's, Ballard (2000) realized that invariantly only half of the tasks in a weekly plan, resulting from the application of the CPM, get realized as planned. This observation, which made the claim of an optimal plan to collapse, led then to development of the Last Planner method, an Aristotelian counterpart to the CPM.

\subsubsection{Construction economics}

The mainstream economic doctrine includes the axiomatic assumption of optimal productive efficiency of firms. This is accepted in the discipline of construction economics. For example, in his book on construction economics, Myers (2004) states, in stark contradiction to the wide evidence on waste in construction:

In any free market economy businesses will never waste inputs. A business will not use 10 units of capital, 10 units of labour, and 10 units of land when it could produce the same amount of output with only 8 units of capital, 7 units of labour, and 9 units of land.

Another example on the deceptive power of an axiomatic starting point is provided by Public Private Partnerships (PPP). They are based on the idea that in creating a single point of responsibility and a long temporal involvement, the PPP model provides an effective economic incentive to implement through life management. However, a recent study could not find substantial evidence on through life management benefits, in spite of wide application of this model over decades in different countries (Koskela \& al. 2016).

\section{CONCLUSION}

The analyses presented show that the Platonic epistemology has dominated in construction engineering and management, leading to various problems and triggering several correctives. However, the common cause for the problems and correctives, namely inappropriate epistemological choices in the form of overuse and misuse of Platonism, has not been explicitly discussed and identified.

It is opportune to remind that Platonism has its lasting value as an approach starting from concepts and ideas; it is thus a better balance between the Platonic and Aristotelian tendencies in construction engineering and management that is needed. For realizing that, a wide discussion in the relevant disciplines and professions is requisite. For enabling future generations of engineers to avoid related problems, it is also suggested that the foundations of epistemology and philosophy of science should be introduced into university teaching. 


\section{REFERENCES}

Ballard, H. G. (2000). The last planner system of production control. Doctoral dissertation, The University of Birmingham.

Brown, T. (2008). Design thinking. Harvard Business Review 86(6): 84.

Clausing, D. (1994). Total quality development: a step-by-step guide to world class concurrent engineering. ASME Press, New York.

Demian, P. \& Fruchter, R. (2006). An ethnographic study of design knowledge reuse in the architecture, engineering, and construction industry. Research in Engineering Design, 16(4), 184-195.

Downey, G. (2005). Are engineers losing control of technology?: From 'problem solving' to 'problem definition and solution in engineering education. Chemical Engineering Research and Design 83(6): 583-595.

Jaafari, A. (1984). Criticism of CPM for project planning analysis. Journal of Construction Engineering and Management 110(2): 222-233.

Koskela, L. (2017) Why is management research irrelevant? Construction Management and Economics, 35 (1-2), 4-23.

Koskela, L., Rooke, J., Siriwardena, M. (2016) Evaluation of the Promotion of Through-Life Management in Public Private Partnerships for Infrastructure. Sustainability, 8, 552.

Koskela, L., Howell, G., Pikas E. and Dave, B. (2014). If CPM is so bad, why have we been using it so long? 22nd Annual Conference of the International Group for Lean Construction, Oslo. Norway, 25 - 27 July 2014, Akademika forlag. Pp. 27 - 37.

Koskela, L., Sacks, R. and Rooke, J. (2012). A brief history of the concept of waste in production. IGCL 20, 18 - 20 July 2012, San Diego, California, USA.

Losee, J. (2001). A Historical Introduction to the Philosophy of Science. Oxford University Press, New York.

Myers, D. (2004). Construction economics: A new approach. Spon Press, London.

OECD. (1972). Eighteenth Annual Report and Resolutions of the Council of Ministers, European Conference of Ministers of Transport. OECD Publishing, $289 \mathrm{p}$.

Rankine, W. J. M. (1872). A manual of applied mechanics. Sixth ed., revised. Charles Griffin, London.

Ross, S. D. (1951). Plato's Theory of Ideas. Oxford University Press, Oxford.

Seely, B. E. (1999). The Other Re-engineering of Engineering Education, 1900-1965. Journal of Engineering Education, 88, 285-294.

Shewhart, W. and Deming, W. (1939). Statistical Method from the Viewpoint of Quality Control. The Graduate School, the Department of Agriculture, Washington.

Shewhart, W. A. (1931). Economic control of quality of manufactured product. D. Van Nostrand Company, New York.

Taguchi, G. \& Clausing, D. (1990). Robust quality. Harvard Business Review, 68(1), 65-75.

Thomke, S. H. (1998). Managing experimentation in the design of new products. Management Science, 44(6), 743-762. 